\title{
An experimental study on drying characteristics and kinetics of figs (Ficus carica)
}

\author{
F. Sabet Sarvestani, A. Rahimi*, M.S. Hatamipour \\ University of Isfahan, Chemical Engineering Department, College of Engineering, P.O. Box 81746-73441, Isfahan, Iran \\ "Corresponding author: e-mail: rahimi@eng.ui.ac.ir
}

\begin{abstract}
In this study, the thin-layer drying characteristics of Figs (Ficus carica) are investigated in a pilot scale forced convective dryer. Experiments carried out under various operating conditions including air temperature $(40,50,60$, $\left.70^{\circ} \mathrm{C}\right)$, air velocity $(0.65,2.1,3.45,4.85 \mathrm{~m} / \mathrm{s})$ and air humidity $(0.005,0.010,0.015 \mathrm{~kg} / \mathrm{kg})$ and the effects of these operating conditions on the drying kinetics and the drying time determined. The obtained kinetics data are fitted into a conceptually developed model. The equilibrium moisture content of the dried figs is determined at different values of temperature and relative humidity of air. The values of effective moisture diffusivity $\left(D_{e f f}\right)$ are obtained from the Fick's second law and a temperature-dependent relation is proposed for this parameter.
\end{abstract}

Keywords: drying kinetics, figs, effective diffusivity, equilibrium moisture content, drying.

\section{INTRODUCTION}

Proper drying techniques could reduce agricultural products losses. The main objective in drying of agricultural products is the moisture content reduction to a level that would prevent rotting and mildewing while allowing safe storage over an extended period. The introduction of new types of dryers in developing countries can reduce agricultural products' deterioration and improve the quality of the dried products significantly when compared to the traditional methods of drying such as sun or shade drying. ${ }^{1}$. A deep knowledge about the behavior of drying kinetics of particular product to be dried is useful for the optimization of the drying performance ${ }^{2}$.

The kinetics of moisture transfer during the drying process depends on operational conditions such as temperature, humidity and velocity of the drying air $^{3}$. Several researchers have investigated the influence of drying conditions on drying kinetics of various agricultural products in order to evaluate different models for describing the thin-layer drying features. Vagenas and Marinos-Kouris ${ }^{4}$ examined the kinetics of apricots using factorial experimental design in order to evaluate the effect of air conditions and pretreatment on the drying time. They found moisture transfer was entirely controlled by external resistance in different air velocities. Kiraoudis et al. ${ }^{5}$ studied the drying kinetics of apple, pear, kiwi and banana, and described a one-parameter empirical mass transfer model involving one drying constant as a function of process variables. Vega et $\mathrm{al}^{3}{ }^{3}$ investigated the hot air drying process of Alovera. They proposed the best empirical model to describe Alovera drying process and evaluated the air temperature effect on the parameters of the selected kinetic model. Azzouz et al. ${ }^{6}$ evaluated the drying kinetics of grapes as a function of drying conditions. They determined the diffusion coefficients of two kinds of grapes. Kaya et al. ${ }^{7}$ conducted research on the quince.

Many researchers have conducted studies on the drying process of various products like green pepper and onion ${ }^{8}$, maize $^{9}$, mushroom ${ }^{10}$, grape ${ }^{11}$ and potato, carrot, pepper, garlic, mushroom, onion, leek, pea, corn, celery, pumpkin, tomato; while studies conducted on drying characteristics of figs are scarce and many of them emphasize only on the effect of air temperature on drying process. Figs are characterized by high sugar level $(16 \%$, fresh) and $(48 \%$, dried $)^{12}$. Figs have a great importance in nutrition since they are very important source of carbohydrates. They contain essential amino-acids and are rich in vitamins $A, B_{1}, B_{2}, C$ and mineral ${ }^{13}$. Nowadays, by increasing the volume of the total production of figs in order to meet the market needs, it is dried artificially by mechanical drying systems by forced convection ${ }^{2}$.

Xanthopolous et al. ${ }^{14}$ evaluated the effective diffusion coefficient of figs. They considered shrinkage and compared the numerical and analytical solution of Fick's second law for unsteady state diffusion. Babalis et al. ${ }^{2}$ used experimental data of drying figs in order to select the best model among several thin-layer drying models available in the related literature. Doymaz ${ }^{13}$ investigated behavior of figs dried under sun and fitted drying data to different mathematical models. Midilli et al. ${ }^{15}$ described a new empirical model for thin-layer drying process and also compared with other single-layer drying models. Most of these models are generally derived by simplifying the general series solutions of Fick's second law. Some of them ended in modified and simplified models fit for temperature, relative humidity, air flow velocity and moisture content ranges for which they were developed ${ }^{16}$.

The objective of this study is to evaluate the effect of the parameters involved in drying process like temperature, humidity and velocity of drying air on the drying kinetics of figs in a forced convection dryer. The two well-known parameters related to drying of figs including the effective diffusivity and the equilibrium moisture content are estimated in this study. Also the principle properties for the moisture removal phenomena are discussed. A conceptually defined kinetics model is proposed to predict the drying kinetics. The model's parameters are obtained based on the experimental data.

\section{MATERIAL AND METHODS}

\section{Sample preparation}

The sample used in this study is a species grown in southern regions of Iran (Estahban, Shiraz). Uniform figs were handpicked from a single orchard. The average initial moisture content was $3.010 .38 \mathrm{~kg} / \mathrm{kg}$ (dry basis) 
and the average geometric initial diameter was $0.034 \mathrm{~m}$. Figs were frozen at $-10^{\circ} \mathrm{C}$ prior the air-drying to keep their initial moisture constant and uniform. Before beginning drying procedure, samples were incubated at room temperature until equilibrium is achieved.

\section{Drying equipment}

The schematic diagram of drying system is illustrated in Figure 1. The system consists of a drying chamber, a centrifugal blower, and a heater. The inlet air was supplied by a centrifugal blower then heated by a set of variable-power electric heaters for temperature control. During the experiments, the ambient temperature, and inlet and outlet temperatures of the drying air in the drying chamber were recorded using a digital thermometer. The mass of samples was measured regularly using a digital balance (Sartarius AY-303) with \pm 0.001 $\mathrm{g}$ accuracy. The inlet air flow was measured using an anemometer (Testo 425 ) with $\pm 0.01 \mathrm{~m} / \mathrm{s}$ accuracy and its relative humidity was measured by Testo 625 with $\pm 3 \% \mathrm{RH}$ accuracy.

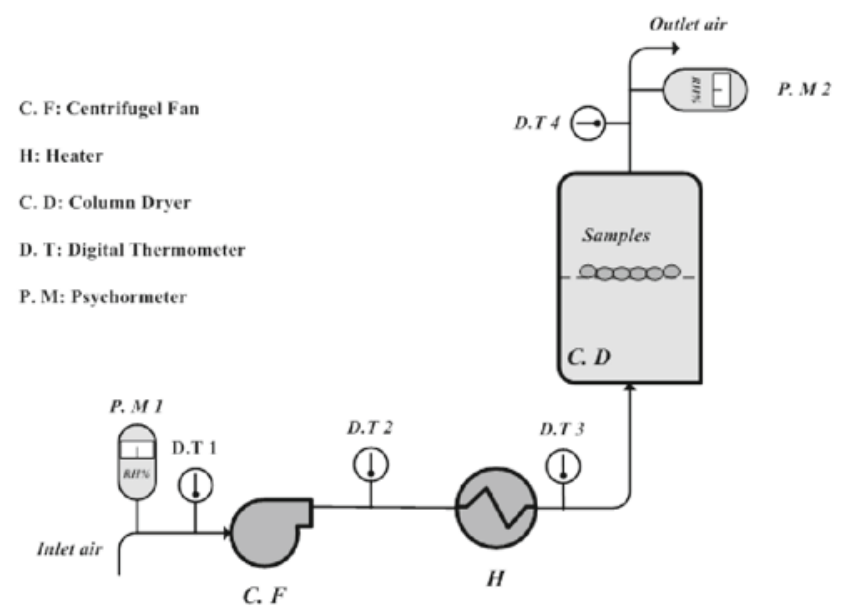

Figure 1. Schematic diagram of the experimental drying system setup

\section{Method of experiments}

In each drying experiment, samples were uniformly put into a drying basket as a single layer. In order to determine the effect of various parameters and the equilibrium moisture content, two sets of experiments were conducted: a total of ten experiments designed to investigate the effect of temperature, humidity and velocity of drying air on drying kinetics, and a total of thirteen experiments designed to obtain the equilibrium moisture content curve of fig samples at different relative humidities and air temperatures. The operating conditions corresponding to each experiment are shown in Table 1 (also in Fig. 2).

A humidifying system was used to control and regulate the humidity of inlet drying air. For this purpose, a bubble type humidifier was used. The humidification tower was a vertical tube including a perforated tube for air bubbling at its bottom and a variable-power immersed electrical heater. The level and temperature of water in the tower were controlled using a thermostat system. In the air humidifier the inlet air temperature increased while it was usually saturated. The saturated air enters the air heater and its temperature increased to a desired value. By controlling the water temperature in the humidifier tower, different values of inlet humidity for drying air could be obtained.

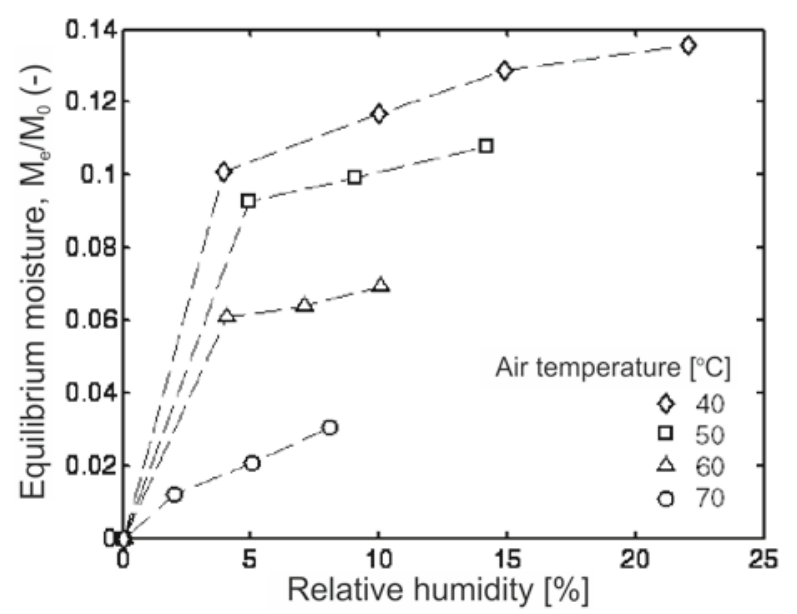

Figure 2. Variation of equilibrium moisture with relative humidity

The procedure of experiments for determining the equilibrium moisture content of figs at a specific temperature and relative humidity of drying air are quite similar to those carried out for drying kinetic study. Initially, a certain amount of figs in thin-layer form were fully exposed to the drying air stream, with a given relative humidity and temperature. The sample weight was measured through drying time using a digital balance. Measurements continued until a constant sample weight was achieved. The value of the final moisture content was reported as the equilibrium moisture content, corresponding to the drying air temperature and relative humidity. The experiments were carried out at four different temperatures.

Table 1. The calculated Deff using method of slope and the proposed model

\begin{tabular}{|c|c|c|c|c|c|c|}
\hline \multirow[b]{2}{*}{$\begin{array}{l}\text { Run } \\
\text { No. }\end{array}$} & \multicolumn{3}{|c|}{ Drying conditions } & \multicolumn{2}{|c|}{ Effective diffusivity coefficient $\left[\mathrm{m}^{2} \mathrm{~s}^{-1}\right]$} & \multirow[b]{2}{*}{$\begin{array}{c}\text { Relative error } \\
{[\%]}\end{array}$} \\
\hline & Temperature $\left[{ }^{\circ} \mathrm{C}\right]$ & $\begin{array}{l}\text { Air velocity } \\
{[\mathrm{m} / \mathrm{s}]}\end{array}$ & $\begin{array}{c}\text { Air humidity } \\
{[\mathrm{kg} / \mathrm{kg}]}\end{array}$ & $\begin{array}{c}D_{\text {eff }} \times\left. 10^{9}\right|_{\text {method of slop }} \\
{[\text { Eq. 3] }}\end{array}$ & $\begin{array}{c}D_{\text {eff }} \times\left. 10^{9}\right|_{\text {proposed model }} \\
{[\text { Eq. 8] }}\end{array}$ & \\
\hline 1 & 40 & 4.81 & 0.005 & 0.829 & 0.837 & 0.9 \\
\hline 2 & 50 & 4.81 & 0.005 & 1.39 & 1.35 & 2.8 \\
\hline 3 & 60 & 4.81 & 0.005 & 2.15 & 2.185 & 1.6 \\
\hline 4 & 70 & 4.81 & 0.005 & 3.2 & 3.21 & 0.3 \\
\hline 5 & 50 & 3.43 & 0.005 & 1.29 & 1.35 & 4.6 \\
\hline 6 & 50 & 2.10 & 0.005 & 1.28 & 1.35 & 5.4 \\
\hline 7 & 50 & 0.68 & 0.005 & 1.22 & 1.35 & 10 \\
\hline 8 & 60 & 3.45 & 0.01 & 2.03 & 2.185 & 7.6 \\
\hline 9 & 60 & 3.45 & 0.015 & 1.95 & 2.185 & 12.0 \\
\hline 10 & 50 & 3.45 & 0.015 & 1.31 & 1.35 & 8.0 \\
\hline
\end{tabular}




\section{MATHEMATICAL MODEL}

\section{Modeling the effective diffusivity coefficient}

The drying of figs was found to occur in the falling rate period only; therefore, the internal moisture diffusion controls the drying process. The effective diffusivity coefficient $\left(D_{\text {eff }}\right)$ of figs is estimated with the Fick's second law represented in Eq. (1):

$\frac{1}{r^{2}} \frac{\partial}{\partial r}\left(r^{2} \frac{\partial M}{\partial r}\right)=\frac{1}{D_{e f f}} \frac{\partial M}{\partial t}$

In the one dimensional spherical system, the solution of the above equation yields to the following equation ${ }^{\mathbf{1 7}}$ :

$M R=\frac{M-M_{e}}{M_{0}-M_{e}}=\frac{6}{\pi^{2}} \sum_{n=1}^{\infty} \frac{1}{n^{2}} \exp \left(-\frac{n^{2} \pi^{2} D_{e f f}}{r^{2}} t\right)$

Eq. (2) is commonly used to estimate the effective diffusivity $^{11,18,19}$. For long drying times (neglecting the higher order terms by setting $n=1$ ), Eq. (2) is simplified to the following linear equation ${ }^{\mathbf{2 0}}$ :

$\ln (M R)=\ln \left(\frac{6}{\pi^{2}}\right)-\left(\frac{\pi^{2} D_{e f f}}{r^{2}}\right) t$

Here, the effective diffusivity is calculated by applying the method of slope ${ }^{21}$. In this method, $\ln (M R)$ is plotted versus time.

\section{Drying kinetic}

A commonly used model is represented here by an equation analogous to Newton's law of cooling ${ }^{22}$ :

$\frac{d M}{d t}=k_{0}\left(M-M_{e}\right)$

In Eq. (4) it is assumed that the moisture transport resistance is uniform all over the particle's surface. The drying rate is proportional to the difference between the moisture content of product being dried and the equilibrium moisture content at a given drying air condition. The drying constant $\left(k_{0}\right)$, combining the effect of the drying conditions, is commonly used.

The drying data were fitted into different mathematical models. The non-linear regression analysis revealed that the Wang-Singh ${ }^{\mathbf{2 3}}$ model results in the best predictions $\left(R^{2}>0.999\right)$. The Wang-Singh model, shown in Eq. (5), is an empirical model derived from a direct correlation between average moisture content and drying time.

$M^{\prime}=c_{1} t^{2}+c_{2} t+c_{3}$

However, this model does not give a clear view of the important processes occurring during drying process although it may describe the drying curve for the conditions of experiments (11) .

The initial moisture content of all runs was not the same. To normalize the moisture content, the experimental data was divided to initial moisture content. The drying rate is obtained as a function of time through differentiation of Eq. (5) as follows (1):

$R_{D}=\frac{d M^{\prime}}{d t}$

In Eq. (4) the drying constant, $k_{0}$, depends on air and material properties ${ }^{24}$. The temperature, air velocity and humidity values dependence of the constant $\left(\mathrm{k}_{0}\right.$ are considered by the following power-law equation ${ }^{25}$ :

$k_{0}=n T^{\alpha} U^{\beta} H^{\gamma}$ where, $T$ is in ${ }^{\circ} \mathrm{C}, U$ is in $\mathrm{m} / \mathrm{s}, H$ is in $\mathrm{kg}$ vapor $/ \mathrm{kg}$ dry air, and $k_{0}$ is in $\mathrm{s}^{-1}$. The model parameters $n, \alpha, \beta$, and $\gamma$ are obtained through fitting procedure.

\section{RESULTS AND DISCUSSION}

\section{The equilibrium moisture content}

Figure 2 shows the variation of dimensionless equilibrium moisture content with relative humidity at air temperatures $40,50,60$, and $70^{\circ} \mathrm{C}$. In this figure, the equilibrium moisture content of figs decreases by an increase in air temperature and a decrease in air relative humidity. As it can be seen in this figure and based on the classification of Brunauer et al., ${ }^{\mathbf{2 6}}$ the behavior of sorption isotherm of figs is according to type I. In this case the water activity that affect directly the equilibrium relative humidity in air layer near the surface of solid increases by any increasing in moisture content of figs. Also the first derivative of this plot increases with moisture content and the curves are convex upwards. This type of sorption isotherm is typically applicable in the process of filling the water monomolecular layer at the internal surface of a material ${ }^{26}$.

\section{Drying curves}

Figure 3 shows the variation of dimensionless moisture content with drying time at $40,50,60,70^{\circ} \mathrm{C}$. As seen, the exponential behavior of drying curves is evident. The drying time decreases by an increase in air temperature. The drying process continues up to the point where the equilibrium moisture content is reached. As seen in Figure 3, there is no constant rate period occurred and all the drying process takes place in the falling rate period. These results are in agreement with the previous researcher's finding $2,3,16$.

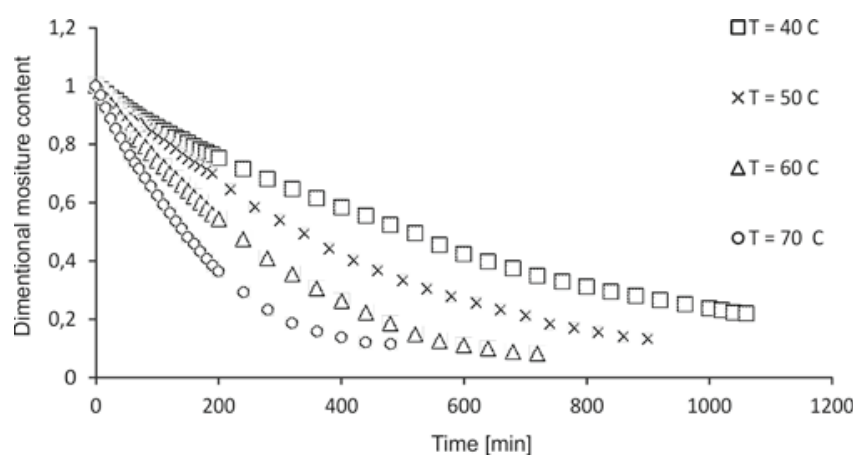

Figure 3. Variation of moisture content with time $(U=4.8 \mathrm{~m} / \mathrm{s}$, $H=0.005 \mathrm{~kg} / \mathrm{kg}$ )

Figure 4 shows the variation of dimensionless moisture content with drying time at four different values of air velocity including $0.65,2.1,3.45$, and $4.8 \mathrm{~m} / \mathrm{s}$. Here, the temperature $\left(50^{\circ} \mathrm{C}\right)$ and the absolute humidity $(0.005 \mathrm{~kg} /$ $\mathrm{kg}$ ) are kept constant for all runs. As seen, the air velocity provides a slight effect on the drying rate. This is because the external resistance moisture transfer from the surface is less important in comparison with the internal resistance ${ }^{27}$. The drying rate is mainly controlled by diffusion of moisture from inside of the products; hence, the effect of air velocity on the drying rate may be negligible.

Figure 5 shows the variation of dimensionless moisture content with drying time for three different values of 


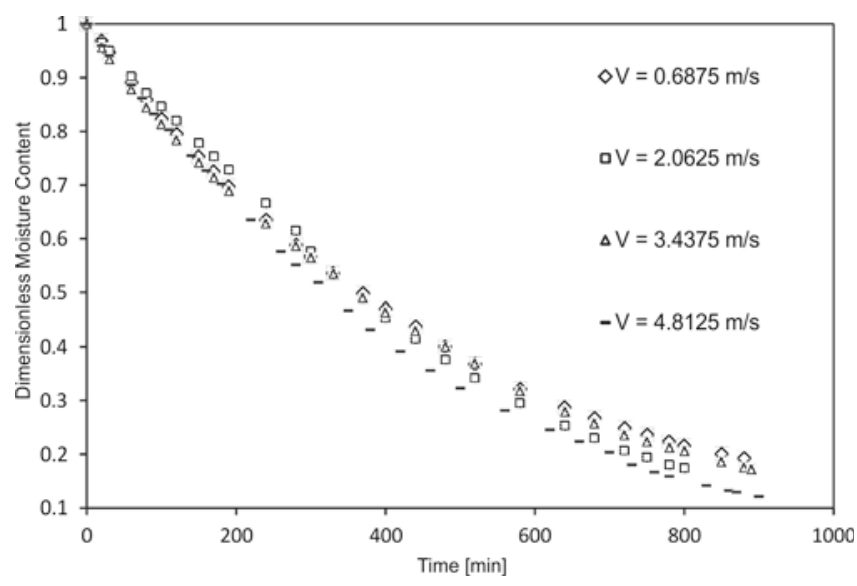

Figure 4. Variation of moisture content with time $\left(T=50^{\circ} \mathrm{C}\right.$, $H=0.005 \mathrm{~kg} / \mathrm{kg}$ )

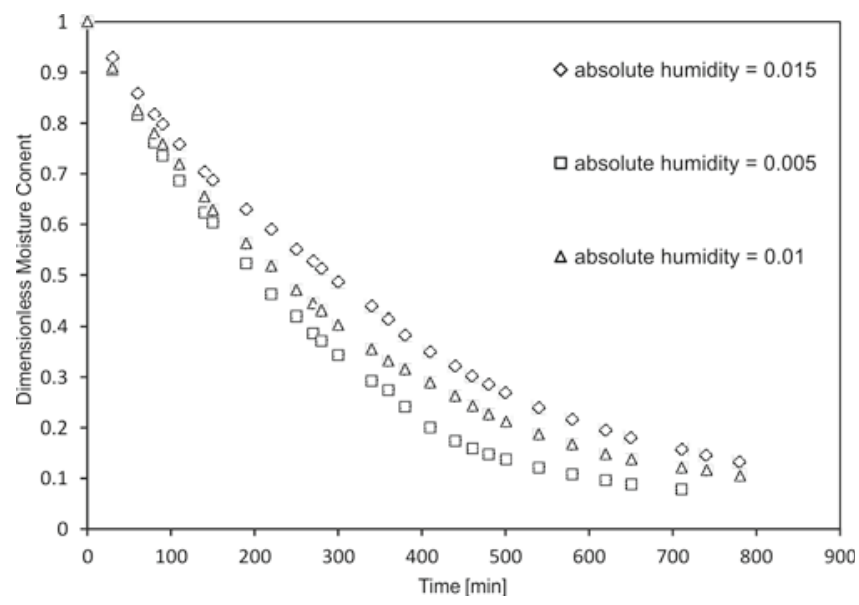

Figure 5. Variation of moisture content with time $\left(T=60^{\circ} \mathrm{C}\right.$, $U=3.45 \mathrm{~m} / \mathrm{s}$ )

air humidity including $0.005,0.01$, and $0.015 \mathrm{~kg} / \mathrm{kg}$. It is found that at constant temperature and air velocity the drying time increases as the humidity of drying air increases; therefore, the drying rate decreases, because the moisture transfer driving force is reduced due to increase in the humidity of drying air. In the studied range of operating conditions, the absolute humidity provides a negligible effect on the drying rate in comparison with the temperature effect.

\section{Effective diffusivity coefficient}

By applying the method of slope derived from Eq. (3), $\ln (M R)$ is plotted versus time in Figure 6 and the values of effective diffusivity coefficient $D_{\text {eff }}$ are calculated. Here, various drying conditions are applied according to Table 1. As can be seen in this figure the behavior of $\ln (\mathrm{MR})$ in

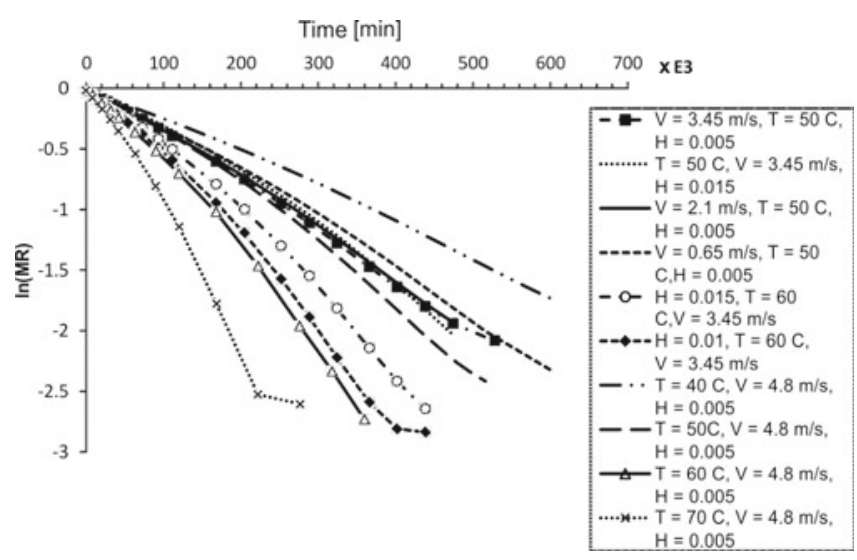

Figure 6. $\ln (M R)$ vs. time at various conditions terms of time is linear. This result indicates that using the method of slope for estimating the effective diffusivity of moisture in figs is sufficiently accurate. It should be reminded that some assumptions including no shrinkage of drying solid and no hardening of solid surface have been considered through developing this method.

In the operating condition range studied, the humidity and velocity of drying air has a negligible effect on the effective diffusivity coefficient in comparison with temperature since the diffusion phenomenon is internally controlled. Therefore, the effective diffusivity coefficient is considered as being dependent on the drying air temperature only. Here, the following equation is proposed: $D_{\text {eff }}=a+b T+\frac{c}{T}$

Where, $T$ is in ${ }^{\circ} \mathrm{C}$. The values of constants $a, b$, and $c$ correlated are shown in Table 2.

Table 2. Values of constants related to Eq. (8)

\begin{tabular}{|l|c|}
\hline Constants & Value $\times 10^{9}$ \\
\hline$a$ & -9.927 \\
\hline$b$ & 0.148 \\
\hline$c$ & 193.6 \\
\hline
\end{tabular}

The obtained values of effective diffusivity coefficient of figs using Eq. (8) along with the calculated relative error percent are reported in Table 1 . The relative error percent is calculated using the following equation:

error $=\frac{\mid \text { calculated value }- \text { experimental value } \mid}{\text { experimental value }} \times 100$

Here, an average $5.3 \%$ error is calculated by Eq. (9) which is acceptable for the proposed model. The obtained values for effective diffusivity coefficient lie within the typical range of $10^{-9}-10^{-11} \mathrm{~m}^{2} / \mathrm{s}$ for food materials ${ }^{2}$. The proposed model predicts satisfactory the effective diffusivity coefficient. Therefore, considering the effective diffusivity as a function of temperature only yields to appropriate results. The effect of temperature on $D_{\text {eff }}$ is more significant than the humidity and the velocity of drying air.

\section{Kinetics model}

In order to estimate the drying kinetics of figs during the drying process Eq. (10) is used:

$\frac{d M^{\prime}}{d t}=k_{0}\left(M^{\prime}-M_{e}^{\prime}\right)$

Where, the solution results in:

$\ln (M R)=\ln \left(\frac{M^{\prime}-M_{e}^{\prime}}{1-M_{e}^{\prime}}\right)=k_{0} t$

Based on the above equation the values of $k_{0}$ are calculated by plotting $\ln (M R)$ versus time at various drying conditions. Since $k_{0}$ is a function of air temperature, air velocity, and air humidity according to Eq. (7), the constants $n, \alpha, \beta$, and $\gamma$ are obtained through fitting procedure. The results are presented in Table 3. As seen in this table, the effect of temperature on the drying rate constant is more significant than that of the absolute humidity and the air velocity.

Table 3. Values of constants related to Eq. (11)

\begin{tabular}{|l|l|}
\hline Constants & Value \\
\hline$n$ & $7.47 \times 10^{-10}$ \\
\hline$\alpha$ & 2.56 \\
\hline$\beta$ & 0.08378 \\
\hline$\gamma$ & -0.142 \\
\hline
\end{tabular}


Table 4. Summary of fitting results for each run with error values

\begin{tabular}{|l|c|c|c|c|c|c|}
\hline $\begin{array}{l}\text { Run } \\
\text { No. }\end{array}$ & Temperature $\left[{ }^{\circ} \mathrm{C}\right]$ & $\begin{array}{c}\text { Air velocity } \\
{[\mathrm{m} / \mathrm{s}]}\end{array}$ & $\begin{array}{c}\text { Air humidity } \\
{[\mathrm{kg} / \mathrm{kgdry} \text { air] }}\end{array}$ & $\begin{array}{c}k_{0}\left[\mathrm{~s}^{-1}\right] \\
\text { obtained from Eq. [11] }\end{array}$ & $k_{0}=n T^{\alpha} U^{\beta} H^{\gamma}\left[\mathrm{s}^{-1}\right]$ & $\begin{array}{c}\text { Relative } \\
\text { Error }[\%]\end{array}$ \\
\hline 1 & 40 & 4.81 & 0.005 & $2.832 \times 10^{-5}$ & $2.575 \times 10^{-5}$ & 9.1 \\
\hline 2 & 50 & 4.81 & 0.005 & $4.706 \times 10^{-5}$ & $4.59 \times 10^{-5}$ & 2.5 \\
\hline 3 & 60 & 4.81 & 0.005 & $7.353 \times 10^{-5}$ & $7.358 \times 10^{-5}$ & 0.1 \\
\hline 4 & 70 & 4.81 & 0.005 & $1.09 \times 10^{-4}$ & $1.097 \times 10^{-4}$ & 0.6 \\
\hline 5 & 50 & 0.68 & 0.005 & $3.836 \times 10^{-5}$ & $3.74 \times 10^{-5}$ & 2.5 \\
\hline 6 & 50 & 2.10 & 0.005 & $4.024 \times 10^{-5}$ & $4.196 \times 10^{-5}$ & 4.3 \\
\hline 7 & 50 & 3.45 & 0.005 & $4.057 \times 10^{-5}$ & $4.42 \times 10^{-5}$ & 8.9 \\
\hline 8 & 60 & 3.45 & 0.010 & $6.89 \times 10^{-5}$ & $6.509 \times 10^{-5}$ & 5.5 \\
\hline 9 & 60 & 3.45 & 0.015 & $5.945 \times 10^{-5}$ & $6.185 \times 10^{-5}$ & 4.0 \\
\hline 10 & 60 & 3.45 & 0.005 & $7.976 \times 10^{-5}$ & $7.10 \times 10^{-5}$ & 11.0 \\
\hline
\end{tabular}

Table 4 presents a summary of drying conditions applied for determining $k_{0}$. In this table, the values of $k_{0}$ obtained from Eq. (11) and those calculated by Eq. (7) are compared and an average $4.9 \%$ error is determined. It is noteworthy that, here, two sets of experiments including Run No. (4) and (10) are not used in the present fitting procedure. The corresponding drying rate data for these two experiments will be used to evaluate the accuracy of the drying rate model which is obtained through Eq. (10).

Figures 7-9 show the variation of experimental drying rate $d M^{\prime} / d t$ with the predicted values of $n T^{\alpha} U^{\beta} H^{\prime}\left(M^{\prime}-M_{e}^{\prime}\right)$ at different drying conditions. As seen, a good agreement between the experimental data and the model's prediction is revealed.

Two sets of experimental data (Run No. 4 and 10) which are not used from the fitting process are applied here in order to examine the model accuracy. Figure 10

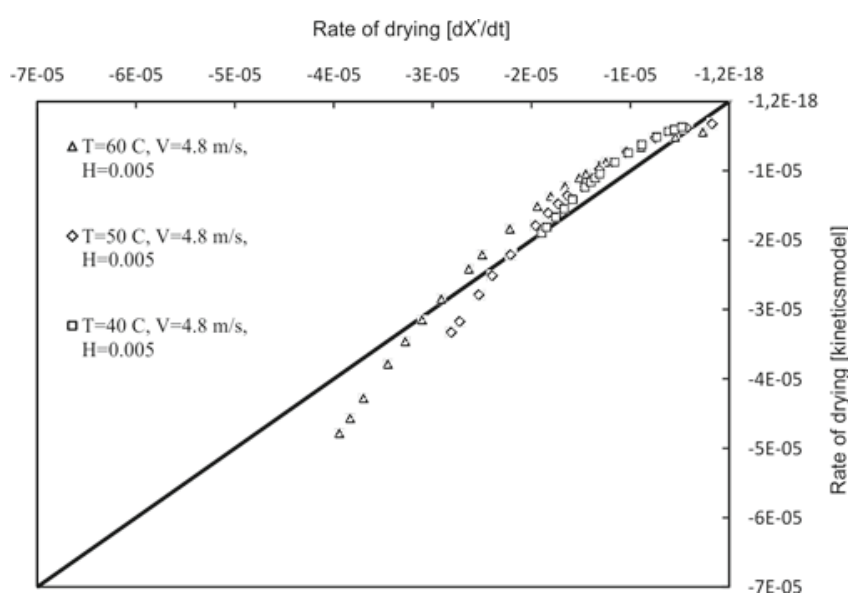

Figure 7. Comparison between experimental values of $d M^{\prime} / d t$ and predicted values of $n T^{\alpha} U^{\beta} H^{\prime}\left(M^{\prime}-M^{\prime} e\right)$ at different temperatures

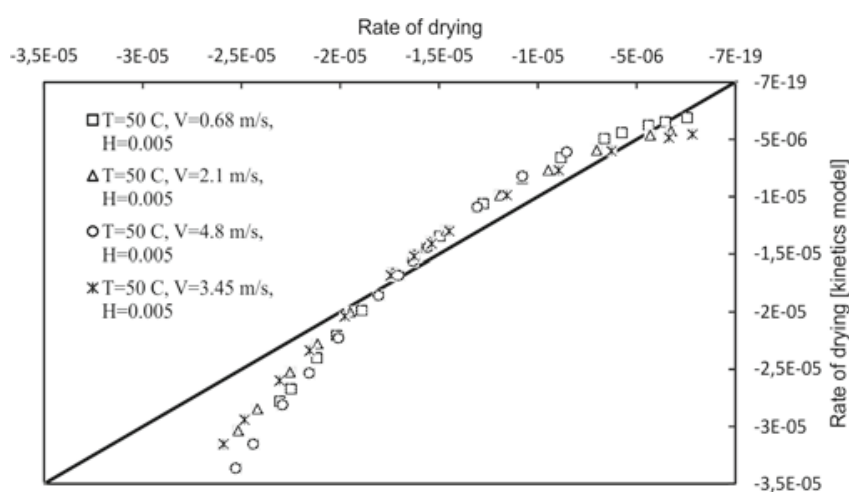

Figure 8. Comparison between experimental values of $d M^{\prime} / d t$ and predicted values of $n T^{\alpha} U^{\beta} H^{\prime}\left(M^{\prime}-M^{\prime} e\right)$ at different air velocities

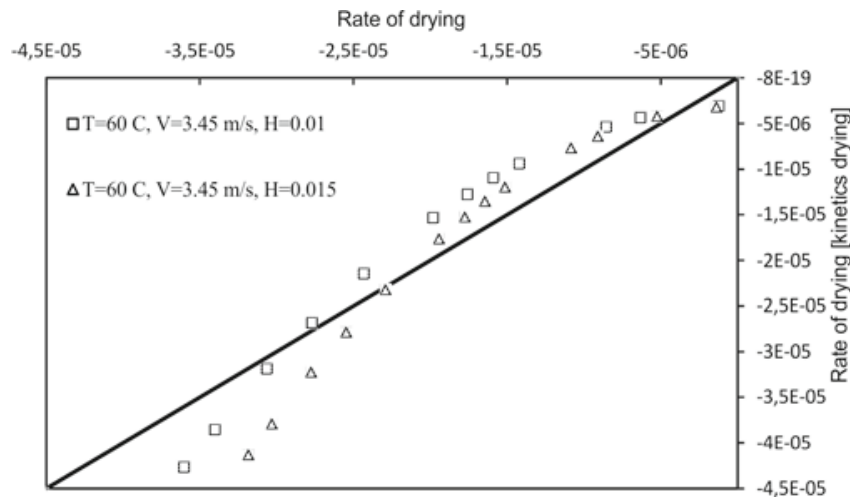

Figure 9. Comparison between experimental values of $d M^{\prime} / d t$ and predicted values of $n T^{\alpha} U^{\beta} H^{\prime}\left(M^{\prime}-M^{\prime} e\right)$ at different air humidities

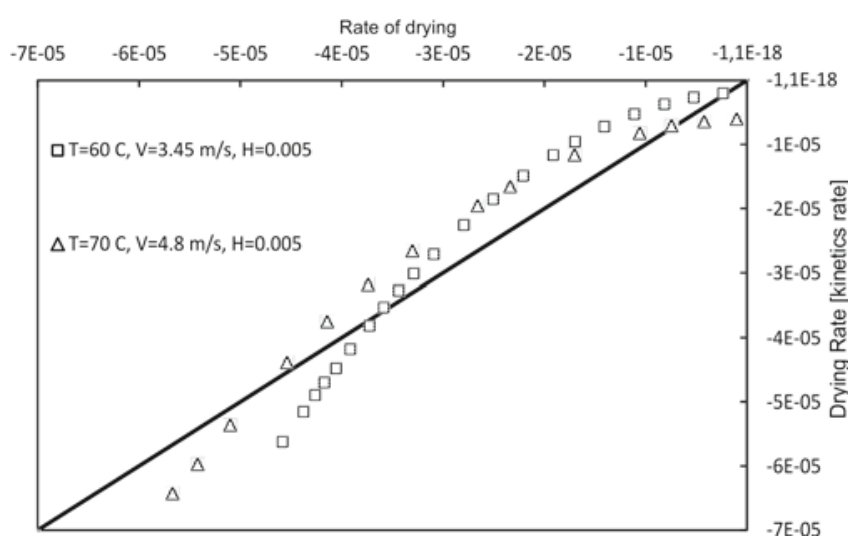

Figure 10. Comparison between experimental values of $d M^{\prime} / d t$ and predicted values of $n T^{\alpha} U^{\beta} H^{\prime}\left(M^{\prime}-M^{\prime} e\right)$ for Run No. 4 and 10

shows the comparison between $d M^{\prime} / d t$ and $n T^{\alpha} U^{\beta} H^{\prime}\left(M^{\prime}\right.$ $-M_{e}^{\prime}$ ) for these two experimental set. According to this figure, the model well predicts the drying rate for the applied two sets of experimental data.

\section{CONCLUSION}

The drying rate of figs is found to be dependent on the operating conditions like temperature, air velocity and humidity while the effect of temperature on drying rate is more significant than the two others

A temperature-dependent equation is proposed to describe the effective diffusivity coefficient. This simple equation well predicts $D_{\text {eff }}$ with an average $5.3 \%$ error

A conceptually defined kinetics model as a function of operational conditions is proposed to predict the drying rate of figs.

There is no constant drying rate period occurred during the drying of figs. The drying rate is controlled mainly 
by diffusion of moisture from inside of the products; hence, the effect of air velocity on the rate of drying can be neglected

\section{NOMENCLATURE}

$a, b, c \quad-$ constants $(-)$

$c_{1}, c_{2}, c_{3} \quad$ - constants (-)

$D_{\text {eff }} \quad-$ effective diffusivity $\left(\mathrm{m}^{2} \mathrm{~s}^{-1}\right)$

$\gamma, \beta, \alpha, n$ - model's constants

$H \quad-$ absolute humidity of drying air (kg vapor/ kg dry air)

$k_{0} \quad$ - drying rate constant $\left(\mathrm{s}^{-1}\right)$

$M \quad-$ moisture content $(\mathrm{kg} / \mathrm{kg}$ dry solid $)$

$M^{\prime} \quad-$ moisture content per initial moisture content

$M R \quad$ - moisture ratio

$R H \quad$ - relative humidity

$R_{D} \quad$ - rate of drying

$r \quad$ - product radius $(\mathrm{m})$

$T \quad-$ air temperature $\left({ }^{\circ} \mathrm{C}\right)$

$t \quad-$ time (s)

$U \quad-$ air velocity $\left(\mathrm{m} \mathrm{s}^{-1}\right)$

\section{Subscripts}

$\begin{array}{ll}\text { exp } & - \text { experiment } \\ \mathrm{e} & - \text { equilibrium } \\ \text { pre } & - \text { predicted }\end{array}$

\section{LITERATURE CITED}

1. Akpinar, E.K., Bicer, Y. \& Yildiz, C. (2003). Thin layer drying of red pepper. J. Food Eng. 59(1), 99-104. DOI: 10.1016/ s0260-8774(02)00425-9.

2. Babalis, S.J., Papanicolaou, E., Kyriakis, N. \& Belessiotis, V.G. (2006). Evaluation of thin-layer drying models for describing drying kinetics of figs (Ficus carica). J. Food Eng. 75(2), 205-214. DOI: 10.1016/j.jfoodeng.2005.04.008.

3. Vega, A., Uribe, E., Lemus, R. \& Miranda, M. (2007). Hot-air drying characteristics of Aloe vera (Aloe barbadensis Miller) and influence of temperature on kinetic parameters. LWT - Food Sci. Technol.40(10), 1698-1707. DOI: 10.1016/j. lwt.2007.01.001.

4. Vagenes, G.K. \& Marinos-Kouris, D. (1991). Drying kinetics of apricots. Drying Technol. 9(3), 735-752. DOI: 10.1080/07373939108916707.

5. Kiranoudis, C.T., Tsami, E., Maroulis, Z.B. \& MarinosKouris, D. (1997). Drying kinetics of some fruits. Drying Technol. 15(5), 1399-1418. DOI: 10.1080/07373939708917300.

6. Azzouz, S., Guizani, A., Jomaa, W. \& Belghith, A. (2002). Moisture diffusivity and drying kinetic equation of convective drying of grapes. J. Food Eng. 55(4), 323-330. DOI: 10.1016/ s0260-8774(02)00109-7.

7. Kaya, A., Aydin, O., Demirtas, C. \& Akgun, M. (2007). An experimental study on the drying kinetics of quince. Desalination 212(1-3), 328-343. DOI: 10.1016/j.desal.2006.10.017.

8. Kiranoudis, C.T., Maroulis, Z.B. \& Marinos-Kouris, D. (1992). Drying kinetics of onion and green pepper. Drying Technol. 10(4), 995-1011. DOI: 10.1080/07373939208916492.

9. Courtois, F., Lebert, A., Duquenoy, A., Lasseran, J.C. \& Bimbenet, J.J. (1991). Modelling of drying in order to improve processing quality of maize. Drying Technol. 9(4), 927-945. DOI: $10.1080 / 07373939108916728$.

10. Xanthopoulos, G., Lambrinos, G. \& Manolopoulou, H. (2007). Evaluation of thin-layer models for mushroom (agaricus bisporus) drying. Drying Technol. 25(9), 1471-1481. DOI: 10.1080/07373930701537179.
11. Pahlavanzadeh, H., Basiri, A. \& Zarrabi, M. (2001). Determination of parameters and pretreatment solution for grape drying. Drying Technol. 19(1), 217-226. DOI: 10.1081/ DRT-100001363.

12. Xanthopoulos, G., Yanniotis, S. \& Lambrinos, G. (2010). Study of the drying behaviour in peeled and unpeeled whole figs. J. Food Eng. 97(3), 419-424. DOI: 10.1016/j. jfoodeng.2009.10.037.

13. Doymaz, I. (2005). Sun drying of figs: an experimental study. J. Food Eng. 71(4), 403-407. DOI: 10.1016/j.jfoodeng.2004.11.003.

14. Xanthopoulos, G., Yanniotis, S. \& Lambrinos, G. (2009). Water diffusivity and drying kinetics of air drying of figs. Drying Technol. 27(3), 502-512. DOI: 10.1080/07373930802686149.

15. Midilli, A., Kucuk, H. \& Yapar, Z. (2002). A new model for single-layer drying. Drying Technol. 20(7), 1503-1513. DOI: 10.1081/DRT-120005864.

16. Panchariya, P.C., Popovic, D. \& Sharma, A.L. (2002). Thin-layer modelling of black tea drying process. J. Food Eng. 52(4), 349-357. DOI: 10.1016/s0260-8774(01)00126-1.

17. Crank, J., The Mathematics of Diffusion. 2 ed. 1975, Oxford: Clarendon Press.

18. Tunde-Akintunde, T.Y. \& Ogunlakin, G.O. (2011). Influence of drying conditions on the effective moisture diffusivity and energy requirements during the drying of pretreated and untreated pumpkin. Energy Convers. Manage. 52(2), 1107-1113. DOI: 10.1016/j.enconman.2010.09.005.

19. Raghavan, G.S.V., Tulasidas, T.N., Sablani, S.S. \& Ramaswamy, H.S. (1995). A Method of determination of concentration dependent effective moisture diffusivity. Drying Technol. 13(5-7), 1477-1488. DOI: 10.1080/07373939508917034.

20. Ghalavand, Y., Hatamipour, M.S. \& Rahimi, A. (2011). Kinetics study of green peas drying in a spouted bed in the presence of a heat carrier. Drying Technol. 29(14), 1648-1655. DOI: 10.1080/07373937.2011.595564.

21. Perry, R. \& Green, D. (1984) Perry's Chemical Engineering Handbook. 6, New York: McGraw-Hill Inc.

22. Temple, S.J. \& van Boxtel, A.J.B. (1999). Thin layer drying of black tea. J. Agr. Eng. Res. 74(2), 167-176. DOI: 10.1006/jaer.1999.0448.

23. Wang, C.Y. \& Singh, R.P. (1978). Use of variable equilibrium moisture content in modeling rice drying. Trans. Am. Soc. Agric. Eng. 11, 668-672.

24. Sander, A., Kardum, J.P. \& Skansi, D. (2001). Transport properties in drying of solids. Chem. Biochem. Eng. Q. 15(3), 131-137.

25. Ertekin, C. \& Yaldiz, O. (2004). Drying of eggplant and selection of a suitable thin layer drying model. J. Food Eng. 63(3), 349-359. DOI: 10.1016/j.jfoodeng.2003.08.007.

26. Brunauer, S., Emmett, P.H. \& Teller, E. (1938). Adsorption of gases in multi molecular layers. J. Am. Chem. Sot. 60(2), 309-319. DOI: 10.1021/ja01269a023.

27. Babalis, S.J. \& Belessiotis, V.G. (2004). Influence of the drying conditions on the drying constants and moisture diffusivity during the thin-layer drying of figs. J. Food Eng. 65(3), 449-458. DOI: 10.1016/j.jfoodeng.2004.02.005. 